\title{
Prevalence of Parasitic Infections in Patients Attending Tertiary Hospital ASCOMS Jammu
}

\author{
Jyoti Kohli', Ajay Puri' ${ }^{2}$, Ashok Dhar ${ }^{3}$ \\ ${ }^{1}$ Associate Professor, Department of Microbiology, ASCOMS Jammu, ${ }^{2}$ Associate Professor, Department of Biochemistry, ASCOMS Jammu, ${ }^{3}$ Professor, Department \\ of Microbiology ASCOMS Jammu.
}

\section{Abstract}

Background: Intestinal parasitic infections are endemic worldwide and varies considerably from place to place. According to World health organization two billion people are infected with parasitic infections globally. This prevalence is due to low levels of sanitation, open defecation, lack of safe water supply, poor hygiene, low socio- economic status, age group and impoverished health services. Subjects and Methods: In order to know the infection rate of these intestinal parasites 2500 stool specimens were studied microscopically for parasitic infections by direct wet mount and iodine mount. Results: It was observed that only $5.28 \%$ were infected with intestinal parasites. The ova and cysts of various intestinal parasites were identified microscopically and pattern of different isolated parasites were studied and it was observed that most commonly isolated was Giardia intestinalis $69.69 \%$, followed by Entamoeba histolytica 19.69\%, Ascaris lumbricoides $7.57 \%$, Ankylostoma duodenale $1.51 \%$ and Trichuris trichuira $1.51 \%$. Conclusion: The decrease in parasitic infections evidence the success of health education, improved sanitation and healthy lifestyle.

Keywords: Intestinal parasitic infections, Ascaris lumbricoides, Giardia intestinalis, Entamoeba histolytica, Trichuris trichiura, Ankylostoma duodenale.

Corresponding Author: Dr. Ajay Puri, Associate Professor, Department of Biochemistry, ASCOMS, Jammu.

Email: puria062@gmail.com

Received: November 2019

Accepted: December 2019

\section{Introduction}

Intestinal Parasitic infections of human is an important threat to healthy living developing countries like India depending upon the socioeconomic status of population and the hygienic conditions. ${ }^{[1]}$ The environmental and sociocultural habits of the people could be attributable for high prevalence of parasitic infections in developing countries. ${ }^{[2]}$ These infections causing clinical morbidity in 450 million people including women of reproductive age group and children. ${ }^{[3]}$ These infections are most common among school going children. ${ }^{[4]}$ More than 1 people are infected with soil transmitted helminthes. ${ }^{[5]}$ Soil transmitted helminthiasis is caused by chronic infection with Nematodes like Ascaris lumbricoides, hook worm and Trichuris trichiura6. Most of the affected people are at increased risk of iron deficiency anemia, Protein energy malnutrition growth defects in children, low pregnancy weight gain and Intrauterine growth retardation followed by low body weight. ${ }^{[7-9]}$

Although there is lot of development in treatment and control of these intestinal parasites take place but still these infections are most important problem encountered in most of the countries. The changing life style, human behavior and concept of hygiene such as handwashing before and after cooking food and also food habits has influenced the prevalence of these intestinal parasites.

\section{Subjects and Methods}

The retrospective study of three year duration from September 2016 to September 2019 was conducted in patients attending outpatient and inpatient departments of Acharya Shree Chander College of Medical Sciences and Hospital after seeking permission from local review board of the hospital in order to study the various intestinal parasites in the stool specimen for routine examination and pattern of different isolated intestinal parasites was studied.

\section{Inclusion criteria:}

Patients with abdominal pain, fever, tenesmus, diarrhea, dysentery, pallor.

\section{Exclusion criteria:}

Stool specimens contaminated with urine and soil. Specimen collection- Stool specimens should be collected in a wide mouthed, clean, leak proof, screw capped a small sterile plastic container with wooden scoop and should be handled carefully to avoid acquiring infection from organisms present in stool before the institution of antiparasitic drugs. At least three consecutive stool specimens on alternate days are required to examine microscopically. ${ }^{[10]}$ Direct wet mount including saline and 
iodine mount by using normal saline and Lugols iodine were made respectively and microscopic examination under 10x and 40x was done to identify the various eggs, ova and cysts. ${ }^{[11]}$ If parasite output is low then the stool specimens need to be concentrated by sedimentation and saturated salt solution floatation method. Eggs, cysts and larvae recovered after concentration procedures but trophozoites get destroyed. By sedimentation method cysts of protozoa and eggs of helminthes settle down at the bottom after centrifugation because of greater density than the suspending medium.

Saturated salt floatation technique: In this $4 \mathrm{gm}$ of feces put in flat bottom container and add few drops of saturated salt solution of 1.200 specific gravity to make smooth solution .To this more salt solution is added to fill the container up to the brim. Place a glass slide over convex meniscus formed on the top of the container. After which glass slide is lifted quickly, then put the cover-slip and examine under the microscope.

\section{Results}

Table 1: Total number of cases studied in percentages

\begin{tabular}{|l|l|}
\hline Positive cases & Negative cases \\
\hline $132(5.28 \%)$ & $2368(94.72 \%)$ \\
\hline
\end{tabular}

Table 2: Percentage and number of protozoans and helminthes

\begin{tabular}{|l|l|}
\hline Percentage of protozoans & Percentage of helminthes \\
\hline $118(89.39 \%)$ & $14(10.60 \%)$ \\
\hline
\end{tabular}

\begin{tabular}{|l|l|}
\hline Table 3: Percentage of sex distribution of infected patients \\
\hline Percentage of males & Percentage of females \\
\hline $90(68.1 \%)$ & $42(31.8 \%)$ \\
\hline
\end{tabular}

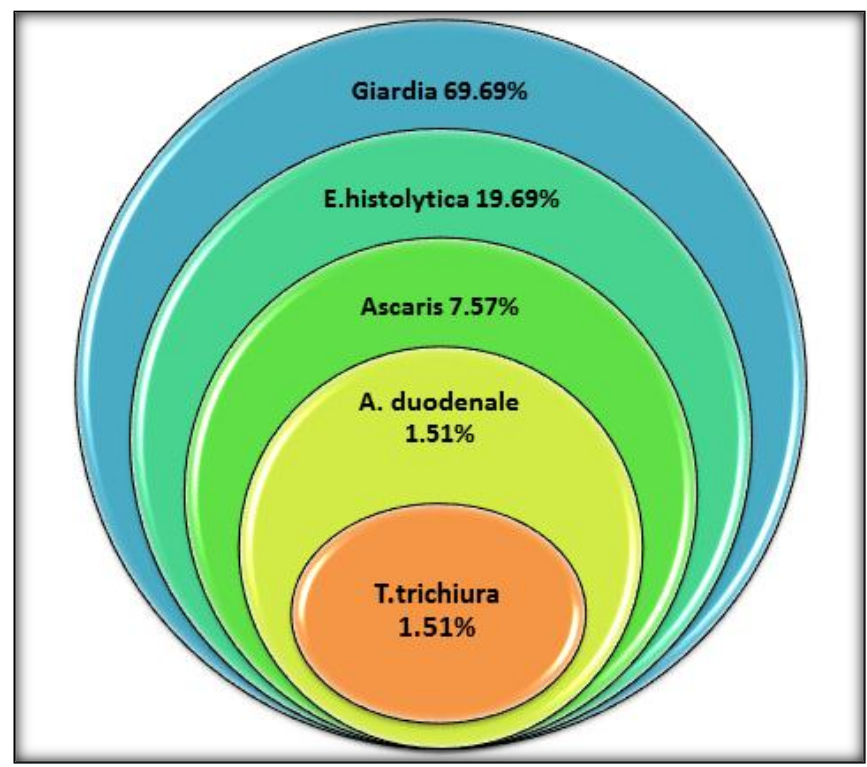

Figure 1: Distribution pattern of different intestinal parasites

Total number of 2500 stool specimens were studied microscopically for parasitic infections and it was observed that 132 i.e.5.28\% were presenting with parasitic infestations and rest 2368 i.e. $94.72 \%$ were negative as shown in [Table 1]. Out of this- $118(89.39 \%)$ were suffering from infestation with protozoa and $14(10.60 \%)$ were found to be helminthic infections as shown in [Table 2 $\&$ Figure 1] showed most commonly encountered among these were Giardia intestinalis 92 ( 69.69\%), followed by Entamoeba histolytica 26 (19.69\%), Ascaris lumbricoides $10(7.57 \%)$ and not the least $2(1.51 \%)$ Trichuris trichuira and $2(1.51 \%)$ Ankylostoma duodenale. In the present study [Table 3] revealed that the parasitic infection was most commonly seen in males $68.1 \%$ as compared to females $31.8 \%$. In this study it was also observed in [Figure 2] that children of age group 4-18years were mostly affected i.e.58 $(43.93 \%)$ as compared to children of less than 4 years and adults of more than 18 years i.e.28 $(21.21 \%)$ and 46 $(34.84 \%)$ respectively.

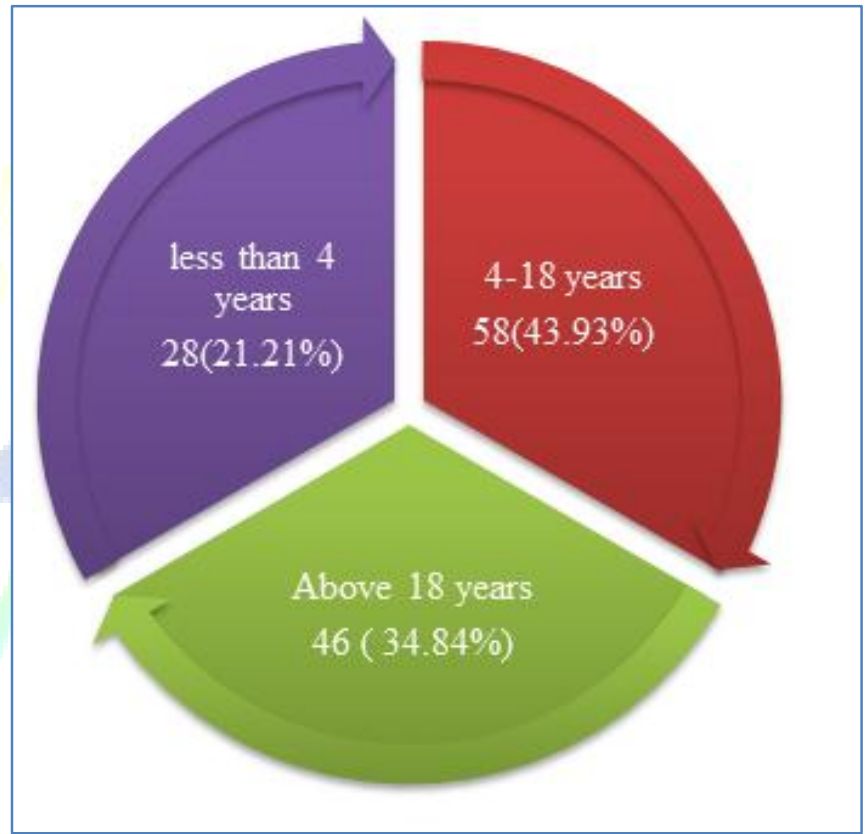

Figure 2: Distribution of intestinal parasites among different age groups

\section{Discussion}

In the present study it was observed that the pattern of intestinal parasitic infections was changing because of lifestyle, human behavior, more awareness, concept of hygiene, sanitary improvement. ${ }^{[12-14]}$ The prevalence rate of parasitic infections in India ranges from $2.5 \%$ to $66 \%$ with varying prevalence for individual parasites. ${ }^{[15-17]}$ In the present study results showed the prevalence of parasitic infections was $5.28 \%$ which was nearly equivalent with the study done by Beena Jad et al i.e. $3.7 \%,{ }^{[18]}$ and quite lower with the studies done by Ragunathan et $\mathrm{al}^{[19]}$ and by Davane et al. ${ }^{[20]}$ It was observed that Giardia intestinalis was the most common intestinal parasite encountered followed by Entamoeba histolytica which resembles with other studies as done by Beena Jad et al. This was most probably due to consumption of contaminated food and 
water and it was the most common environmental contaminant. Several outbreak of Giardia intestinalis resulted with the consumption of contaminated water supply. The prevalence rate of Giardiasis was $2-5 \%$ in developed countries and $20-30 \%$ in developing countries. ${ }^{[7]}$ The Trichuriasis were less prevalent in this region as compared to other regions of India due to sociodemographic factors and also of socioeconomic factors. In the present study ova or cysts of different parasites studied were seen mostly in the age group of 5- 15 years i.e, school going children were mostly affected. Adults were found to be least affected because of more awareness and concept of hygiene. Males show relatively high incidence of parasitic infections as such there was no relation with sex and showed similar results with study done by Singh et al, ${ }^{[17]}$ and Beena Jad et al, ${ }^{[18]}$ where males exhibited high prevalence of intestinal parasitic infections. $66.66 \%$ due to their frequent migratory behavior which provides greater chance of parasitic exposure. ${ }^{[21]}$ The male to female ratio was $2.14: 1$. The most commonly encountered were Giardia intestinalis followed by Entamoeba histolytica, Ascaris lumbricoides, Ankylostoma duodenale and Trichuris trichuira. The incidence of hook worm and Taenia had decreased due to changing lifestyle of people.

\section{Conclusion}

The saddle of disease is related to less mortality than to the chronic and subtle effects on health and nutritional status of the host. ${ }^{[22]}$ Parasitic infections not only damages physical and mental development of children but also prevent educational achievement and hampers economic development. Henceforth the people should be well educated with concept of good hygiene and provided with better sanitation facilities to curb the life cycle of these parasites. Their life style need to be modified more to get rid of the morbidity and the burden of these parasitic infections in the society. De-worming campaign in the schools has also reduced the prevalence rate.

\section{References}

1. Kia EB, Hossein M, Nilforushan MR, Meamar AR, Rezaeian M. Study of intestinal protozoan parasites in rural inhabitants of Mazandaran province, Northern Iran. Iranian J Parasitol. 2008;3: 22-25.

2. Mbanugo JI, Onyebuchi CJ. Prevalence of intestinal parasites in Ezinifite community, Aguata state. Nigerian J. Parasitol.2002; 27- 34.

3. Valencia QL, Crompton ME, Phillips DW, Hagan S, Morales P, Camecho D. Role of the employment status and education of mothers in the prevalence of intestinal parasitic infections in Mexican rural school children. BMC Public Health 2006;6:225-9.

4. Savioli L, Bundy D, Tomkins A. Intestinal parasitic infections: a soluble public health problem . Tram R Soc Trop Med Hyg 1992;86:353- 354.

5. Bethony J, Brooker S, Albonico M. Soil transmitted helminth infections: Lancet 2006; 1521- 32.

6. Albonico M, Crompton DW, Savioli L. Control Stratagies for human intestinal nematode infections. Adv Parasitol, 1992;42:277- 341.

7. Stephenson LS, Latham MC, Ottesen ED. Malnutrition and parasitic helminthic infections. Parasitology 2000;121:523- 538.

8. Sackey ME, Weigel MM, Armijos RX. Predictors and nutritional consequences of intestinal parasitic infections in rural Ecuadorian children . J Trop Pediatr. 2003; 49: 17- 23.

9. Rodriguez-Morales AJ, Barbella RA, Case C. Intestinal parasitic infestations among pregnant women in Venezuela. Infect Dis Obstet Gynecol. 2006; 23125: 1 - 5.

10. Sastry AS, Bhat S. Essentials of Medical Parasitology. 2nd edition.2019 ISBN: 978- 93- 5270- 480- 4 pg; 253- 257.

11. Chatterjee KD. A textbook of parasitology, protozoology and helminthology (CBS publishers and distributers Pvt Ltd, New Delhi, India, 2009) 260- 265.

12. Mowlavi GR, Ahmadi HM, Rezaeian M, Beigom E, Kia, N EbrahimiDaryani, Rohini MB. The prevalence of intestinal parasites in tribal parts of Khuzestan - province. Scientific Journal of Iranian Association of Gastroenterology and hepatology (Goverash)2008; 12(4): 219- 28.

13. Rajeswary B, Sinniah B, Hasnah H. Socio- economic factors associated with intestinal parasite among children living in Gombak, Malaysia. Asia Pacific Journal of Public Health, 1994; 7: 21- 25.

14. M Rohini. The present status of human helminthic diseases in Iran . Ann Trop Med Parasitol. 2008; 102 (4): 283-95.

15. Amin AB, Amin BM, Bhagat AP, Patel JC. Incidence of helminthiasis and protozoal infection in Bombay. J Indian Med Assoc 1979; 72: 225 7.

16. Ramesh GN, Malla N, Raju GS, Sehgal R, Ganguly NK, Mahajan RC, et al. Epidemiological study of parasitic infestations in lower socioeconomic group in Chandigarh( North India). Indian J Med Res 1991; 93: 47- 50.

17. Singh S, Raju GV, Samantaray JC. Parasitic gut flora in a North Indian population with gastrointestinal symptoms. Trop Gastroenterol 1993; 14: 104- 8 .

18. Beena Jad, Sandeep Dogra, Bella Mahajan . Significant decrease in prevalence of intestinal parasites among patients seeking treatment in a tertiary care hospital in Jammu a changing trend. Int. J. Curren. Microbiol. App. Sci (2015) 4 (11): 659- 664.

19. Ragunathan L, Kalivaradhan SK, Ramadass S, Nagaraj M, Ramesh M. Helminthic infections in school children in Puducherry, South India. J Microbiol Immunol Infect 2010;43: 228- 32.

20. Davane MS, Suryawanshi NM, Deshpande KD. A prevalence study of intestinal parasitic infections in a rural hospital. Int J Recent Trends Sci Technol 2012; 1- 3.

21. Norhaati M, Fatmah MS, Yusof S, Edariah AB. Intestinal parasitic infections in a man : a review. Med J Malaysia. 2003; 58(2):296- 305.

22. Stolzfus RJ, Chway HM, Montresor A. Low dose daily iron supplementation improves iron status and appetite but not anemia, whereas quarterly antihelminthic treatment improves growth, appetite and anemia in Zanzibari preschool children. J Nutrition 2004;134:348356.

Copyright: (C) the author(s), 2020. It is an open-access article distributed under the terms of the Creative Commons Attribution License (CC BY 4.0), which permits authors to retain ownership of the copyright for their content, and allow anyone to download, reuse, reprint, modify, distribute and/or copy the content as long as the original authors and source are cited.

How to cite this article: Kohli J, Puri A, Dhar A. Prevalence of Parasitic Infections in Patients Attending Tertiary Hospital ASCOMS Jammu. Asian J. Med. Res. 2020;9(1):MB01-MB03.

DOI: dx.doi.org/10.47009/ajmr.2020.9.1.MB1

Source of Support: Nil, Conflict of Interest: None declared. 